\title{
Youths' perceptions of community health workers' delivery of family planning services: a cross-sectional, mixed-methods study in Nakaseke District, Uganda
}

Robert Kalyesubula ${ }^{1,2^{*}}$ (D, Jessica Mitter Pardo ${ }^{3}$, Stephanie Yeh ${ }^{3}$, Richard Munana ${ }^{1,2}$, Ivan Weswa', Joseph Adducci ${ }^{3}$, Faith Nassali ${ }^{1}$, Mennen Tefferi ${ }^{3}$, John Mundaka ${ }^{1}$ and Sahai Burrowes ${ }^{3}$

\begin{abstract}
Background: High rates of unintended adolescent pregnancy are a significant health problem in Uganda. To improve access to family planning (FP) services, community-based Village Health Teams (VHTs) are widely employed in Uganda to deliver education and services. However, evaluations of FP programs suggest that mainly older, married women use VHT FP services.

Methods: To better understand youth reluctance to use VHTs, we collected quantitative FP and contraceptiveseeking behavior data from a survey of 250 youths aged 15-25 in randomly selected households in Nakaseke District, which we triangulated with data from 3 focus group discussions (FGDs) $(n=15)$.

Results: Most respondents received FP services from the formal health sector, not VHTs. Only half had talked to a VHT, but 65\% knew that VHTs provide free FP services, and most (82\%) felt comfortable talking to VHTs about FP. The main reasons for discomfort were fear that VHTs would violate privacy (mentioned by $60 \%$ of those not comfortable), that VHTs would talk to parents (33\%), shyness (mentioned by $42 \%$ of those $\leq 18$ ), and fear of being judged (14\%). Concern about side effects was the most common reason for not using FP methods. Survey respondents said having VHTs of the same sex was important, particularly those in the youngest age group (OR= $4.45 ; 95 \% \mathrm{Cl}: 1.24,16.00)$ and those who were unmarried (OR=5.02; 95\%Cl: 2.42, 10.39). However, FGD participants (who were older than survey respondents on average) often preferred older VHTs of the opposite sex, whom they viewed as more professional and trustworthy. Respondents said the primary deciding factors for using VHTs were whether privacy would be respected, the proximity of care, and the respectfulness of care.

Conclusions: VHTs are a known source of FP services but not widely used by youth due to privacy and quality of care concerns. VHT messaging and training should increase focus on ensuring privacy, protecting confidentiality, providing respectful care, and addressing concerns about contraceptive side effects. Preferences for VHTs of similar age and sex may be more important for younger adolescents than older youths for whom quality concerns predominate.
\end{abstract}

Keywords: Adolescents, Family planning, Contraception, Reproductive health, Community health workers, Uganda

\footnotetext{
* Correspondence: rkalyesubula@gmail.com

${ }^{1}$ African Community Center for Social Sustainability, Nakaseke, Uganda

${ }^{2}$ Makerere University College of Health Sciences, Kampala, Uganda

Full list of author information is available at the end of the article
}

(c) The Author(s). 2021 Open Access This article is licensed under a Creative Commons Attribution 4.0 International License, which permits use, sharing, adaptation, distribution and reproduction in any medium or format, as long as you give appropriate credit to the original author(s) and the source, provide a link to the Creative Commons licence, and indicate if changes were made. The images or other third party material in this article are included in the article's Creative Commons licence, unless indicated otherwise in a credit line to the material. If material is not included in the article's Creative Commons licence and your intended use is not permitted by statutory regulation or exceeds the permitted use, you will need to obtain permission directly from the copyright holder. To view a copy of this licence, visit http://creativecommons.org/licenses/by/4.0/ The Creative Commons Public Domain Dedication waiver (http://creativecommons.org/publicdomain/zero/1.0/) applies to the data made available in this article, unless otherwise stated in a credit line to the data. 


\section{Background}

Although the Ugandan government has made impressive strides in increasing access to sexual and reproductive health (SRH) services for youth over the past 20 years, the unmet need for family planning services remains persistently high. Data from the most recent Uganda Demographic and Health Survey (UDHS) reveals that in 2016 , only $10 \%$ of all women aged $15-19$ and $43 \%$ of sexually active unmarried women in this age group were using a contraceptive method [1]. A quarter of women aged 15-19 had already begun having children [1]. Almost half (45\%) of sexually active unmarried women aged 15-19 reported an unmet need for contraception in the UDHS. More recent data from the Guttmacher Institute suggest that the percentage of women with unmet need in this age group may be higher than $60 \%$ [ 2]. Lack of access to family planning services has been particularly acute in Uganda's rural areas, where the actual fertility rate is 1.3 children higher than the wanted fertility rate, and 1 in 4 females become pregnant between ages 15 and 19 [1].

The negative impact of adolescent and unwanted pregnancy should not be underestimated, as pregnancy and childbirth-related complications are a leading cause of death for females aged 15 to 19 in low-income settings [2, 3]. Pregnant adolescents experience a significantly higher rate of severe neonatal conditions such as preterm delivery, low-birthweight infants, and stillbirth. They also face an increased risk of perinatal systemic infections, eclampsia, and endometritis $[1,3,4]$. In addition, adolescent pregnancy has many economic consequences, including lower educational accomplishment and subsequent reduced vocational opportunities and financial earnings, as well as significant psychosocial consequences such as estrangement from family, depression, and even violence [5-9]. Lack of access to SRH services can also be seen as a violation of sexual and reproductive health rights, which include the right to "decide whether, when and by what means to have a child or children, and how many children to have" [10].

Using modern family planning (FP) methods reduces adolescent pregnancy and its subsequent adverse health and socioeconomic outcomes; however, willingness and ability to access SRH services may be particularly difficult for young populations. Several general barriers to accessing FP services are prevalent in low- and middleincome countries, including long distances to health facilities, high cost, inadequate supplies, and lack of choice in FP methods [11-13]. These barriers may be higher for youth and adolescents, who also face additional obstacles to care, such as provider refusal to deliver care and legal restrictions such as age of consent laws and requirements for spousal or parental permission for certain services [14-16]. In addition to these health systems and policy-level barriers to access, young women in Uganda also face significant social and cultural barriers, including sexual coercion, reproductive coercion, and gender-based violence, which are prevalent in the country [17-19]. Although the evidence is mixed, these forms of violence and coercion severely limit young women's reproductive autonomy and may prevent them from seeking FP services and constrain their choice of FP methods [20-23].

In addition to problems with access, acceptability and demand for services may also be low in young populations due to concerns about privacy, autonomy, and disapproving and judgmental providers [24-26]. Largescale population-based surveys among youth in Kenya and Zimbabwe, for example, have identified that, with regards to SRH services, adolescents cite confidentiality, short wait time, and low cost as important factors in determining their use of FP services [27].

To address these concerns and to encourage the utilization of services, global policymakers have promoted the creation of "youth-friendly" SRH services that have special features such as separate clinic hours and waiting areas for youth [28-31]. However, there remains a relative dearth of such youth-friendly services in Uganda and elsewhere in East Africa. While Uganda's policies allow FP services to be provided without spousal consent or parental consent for adolescents, the policies require prior education on FP method choices [32]. Providing this education to youth has been complicated by the country's recent switch to abstinence-only sexual health education in the public school system $[32,33]$.

Largely absent from policy discussions about expanding youth-friendly FP services is an analysis of how this approach aligns with another strategy commonly employed by health systems in low- and middle-income countries to increase access to, and utilization of, comprehensive FP services, namely the employment of community-based health workers (CHWs) to deliver FP education and services directly to women in their communities. Such "task-sharing" CHW-based initiatives have been credited with facilitating increases in contraception uptake in low- and middle-income countries and have been central in countries that have had dramatic improvements in FP uptake, such as Ethiopia, Malawi, and Rwanda [34-39]. In Uganda, the Ministry of Health organized CHWs into Village Health Teams (VHTs) in 2001, and since that time, CHWs have commonly been referred to as VHTs. VHTs are volunteers elected by their communities, who act as the first point of contact with the health system at the household level. They provide health education, case management of common health conditions, distribution of medicines and supplies, and referral and follow-up services for health facilities. The Ministry requires that VHTs be 
over the age of 18, and most programs that use VHTs also require that they be literate in the local language [40]. In 2011 VHTs were authorized to directly provide SRH services to the public, including delivering an array of contraceptive methods such as condoms, oral contraceptives, emergency contraceptives, and injectables [41, 42]. Since that time, there has been little reporting on how well VHTs have performed at meeting the needs of younger community members for FP services. Outside of Uganda, one of the few CHW FP studies that focused on young women found evidence of $\mathrm{CHW}$ reluctance to provide services to young, married women who had not yet had children. The authors speculate that this reluctance may have been due to a cultural expectation that young women "prove their fertility" early in marriage before spacing births [38].

Our study's motivation is a program led by a Ugandan non-governmental organization, ACCESS-Uganda (African Community Center for Social Sustainability), in which VHTs provide community members with health education and contraceptive supplies and make referrals to primary care health centers for long-acting and permanent contraceptive methods (LAPM). Internal evaluations of the program found that beneficiaries were primarily older and married women or women who had already given birth, rather than younger, unmarried women or nulliparous but sexually active women. We, therefore, undertook this study to investigate how youth in the project area perceived VHT outreach services and to identify barriers to youth utilization of these services. We were particularly concerned to learn about youths' desire for younger, peer VHTs, as community-based family planning programs frequently exclude adolescents from serving as CHWs [38]. Understanding how youths seeking FP services perceive the approachability of CHWs like Uganda's VHTs is crucial for planning and managing the growing number of these initiatives. Such information is particularly crucial for programs operating in rural areas such as our study site, where CHWs may be the only easily accessible sources of comprehensive FP education and services.

\section{Methods}

\section{Study design}

The study used a mixed-method, cross-sectional design. The primary approach was quantitative, employing survey data from randomly selected households, with qualitative focus group data used to inform and explain survey results.

\section{Study setting}

We conducted the study in Nakaseke District. Nakaseke District is a largely rural area located approximately 42 miles from Kampala. The district consists of 15 sub- counties, which are further divided into parishes, villages, and households. The district age distribution is similar to the national distribution: $18 \%$ of the population of nearly 200,000 people are between the ages of 15-24 [43]. Approximately $18 \%$ of young women between 12 and 19 years of age have already given birth. At the time of the study, The ACCESS-Uganda Family Planning program operated in 6 of 15 sub-counties with 98 VHTs estimated to cover approximately 119,339 community members [44].

\section{Participant selection}

One parish was randomly selected from each of the six sub-counties in the ACCESS-Uganda Family Planning program. The number of participants recruited per subcounty was proportional to the youth population size in the sub-county, based on the 2014 National Population and Housing Census [43]. We calculated a sample size of 229 individuals based on Cochran's formula, with a $95 \%$ confidence interval and a 5\% margin of error. We then rounded up the sample size to 250 individuals to account for possible non-response.

We used a random-walk technique for household selection. On arriving at the selected parish, the data collection team continued to travel on the main road leading away from the center. If there were several roads, one was picked at random using a series of coin flips. The data collection team then stopped in at every third village along the road for sampling. The team walked to the center of the village, asking directions if necessary, and then spun a pencil to determine the direction they would travel. They then recruited participants from every third household in that direction, returning to the center to repeat the random walk as necessary. If a selected household did not have persons in the target population available for participation, the data collection team proceeded to the next household for sampling. All youth aged 15-24 who lived in the household were eligible for inclusion in the study, but only one youth per household was selected for the survey on a first-comefirst-served basis.

Participants were asked if they were willing to be contacted for participation in a focus group discussion (FGD) during the consent process. We conducted 3 FGDs $(n=15)$ with respondents purposively selected from the list of willing survey participants to ensure a mix of different sexes, age, parity, and educational status. FGDs were organized by sex into a female, male, and mixed-sex group.

\section{Ethics and approvals}

The study was approved by the Institutional Review Boards at Touro University California (\#PH-0518) and the Mulago Hospital Research and Ethics Committee 
(\#1583). All participants were told the aims of the study, that their participation was voluntary, and that they could withdraw participation at any time without consequences. In addition, written consent or assent for participation was obtained from all participants. Parental permission was also obtained for all respondents under the age of 18. The procedure for obtaining permission from parents and guardians for minors who aggreged to participate in the study was approved by the Institutional Review Boards/Ethics review committees that reviewed the study protocol.

\section{Data collection}

Data collection took place in February and March 2019. The survey instrument and focus group guide were developed by adapting items found in internationally recommended instruments [45] and by reviewing the literature for East Africa-specific constructs to incorporate into the adaptation [27, 46-48]. The instrument contained questions on demographics, sexual and careseeking behavior, barriers to contraceptive use, and knowledge of, and attitudes towards, VHT FP services offered. Both tools were developed in English and then translated into Luganda, the local language for administration (see Supplemental File 1). The surveys contained 32 close-ended questions. Before data collection, the survey was pre-tested with 15 youth to obtain feedback on the difficulty of use, readability, and interpretability.

The survey was interviewer-administered using a paper instrument. Trained students from ACCESS' Health Training Institute of Nursing and Midwifery collected survey data after completing a one-and-a-half-day training on the study's goals, randomization and survey procedures, and research ethics. A Touro University California master's student coordinated data collection under the supervision of ACCESS Uganda's Family Planning program staff and project Principal Investigators. The data collection team and coordinator debriefed after each day in the field to discuss problems and plan the next day's activities. Every evening, the project coordinator entered the survey data into a secure online spreadsheet that the project investigators reviewed, allowing them to flag data quality problems to address in the debriefing sessions.

We conducted three FGDs after the surveys were completed in order to clarify and explain survey findings. The semi-structured focus group guide was revised based on questions that emerged from the preliminary analysis of the survey data. A professional facilitator from the ACCESS team conducted the FGDs in a conversation-like manner, in Luganda, following the guide. The FGDs were held at the ACCESS-Uganda conference room or ACCESS-affiliated health centers after hours. Each took approximately $60 \mathrm{~min}$ to complete and was audio-recorded with informed consent. The project coordinator participated in all three focus group discussions, recording notable comments, documenting participant behavior, and following up on facilitator questions.

\section{Data analysis}

Survey data were entered into a Microsoft Excel spreadsheet, then exported to Stata (version 16) for analysis. We produced descriptive statistics on participant demographics, sexual history, and family planning information and services sources. We also conducted bivariate and multivariate logistic regression to determine factors associated with comfort interacting with VHTs for FP services.

FGD audio transcripts were transcribed verbatim and then translated into English and analyzed thematically. FGD facilitators conducted a brief preliminary analysis after each FGD to identify critical issues to be explored or clarified in subsequent FGDs. The transcripts were read through several times: first by a research assistant (MT) and a project investigator (SB) to develop a codebook of themes in an iterative process based on both the a priori research questions and themes emerging from the data. A second research assistant-investigator team (JMP and SB) then hand-coded paper transcripts and extracted key illustrative quotes to illuminate the themes.

\section{Results}

\section{Sample characteristics}

All 250 sampled households that reported having a youth eligible for inclusion agreed to participate in the study for a reported $100 \%$ response rate. We note, however, that households that did not want to participate may have stated that they did not have eligible household members rather than directly refusing to participate. The sample was relatively old, with only $21 \%$ of respondents aged 18 years or younger and slightly more than one-third over the age of 21 (see Table 1). The mean age was 20.4. Most respondents (72\%) were female, and slightly more than half $(54 \%)$ had completed secondary school reflecting the sample's age structure. Almost all (81\%) were not currently in school. Approximately a third of respondents (29\%) were married. Forty-three percent had children, including $31 \%$ of those $\leq 18$ and $29 \%$ of those $19-21$ years old. The $\leq 18$ age group had had 1.5 children on average.

\section{Sources of family planning education}

Almost all respondents had heard of the term "family planning" at some point in their lives (see Table 2). However, only $63 \%$ had received formal FP education. Of the respondents who had received FP education, $72 \%$ received it from formal healthcare facilities, either at 
Table 1 Sample Characteristics of Youths from Nakaseke District, Uganda

\begin{tabular}{lll}
\hline & Number $(\boldsymbol{n}=\mathbf{2 5 0})$ & Percent \\
\hline Sex (Female) & 178 & $71 \%$ \\
Age Group & 54 & $22 \%$ \\
18 Years of Age or Younger & 111 & $45 \%$ \\
19-21 Years Old & 82 & $33 \%$ \\
Older than 21 Years of Age & & \\
Highest Level of Education & 96 & $38 \%$ \\
Primary & 136 & $54 \%$ \\
Secondary & 10 & $4 \%$ \\
Tertiary & 8 & $3 \%$ \\
None & 203 & $81 \%$ \\
Currently Attending School (No) & & \\
Marital Status & 128 & $51 \%$ \\
Single & 44 & $18 \%$ \\
Unmarried in Relationship & 72 & $29 \%$ \\
Married & 6 & $2 \%$ \\
Divorced/Widowed & 98 & $43 \%$ \\
Have had Children & & \\
\hline
\end{tabular}

hospitals or community clinics. Only $20 \%$ had received FP education from VHTs.

\section{Sexual history and family planning use}

Almost all respondents reported having had a sexual encounter (90\% of all respondents and $70 \%$ of those age 18 and under). A third of the sample reported having had sex by age 15 , and the majority (62\%) had their first sexual encounter between the ages of 15-19 (See Table 3). Most (65\%) were currently having sex, including $47 \%$ of those $\leq 18$. Although most respondents (72\%) had used an FP method in the past, only $55 \%$ of those age 18 and under-reported having ever used an FP method. Most said that they would go to a hospital $(67 \%)$ or a health center (24\%) if they needed FP services. Only 9\% said that they would go to a VHT.

Condoms were the most common family planning method used (see Fig. 1), with injectables and oral
Table 3 Sexual History and Family Planning Use among Youths in Nakaseke District, Uganda

\begin{tabular}{lll}
\hline & Number $(\boldsymbol{n}=\mathbf{2 5 0})$ & Percent \\
\hline $\begin{array}{l}\text { Ever Had Sex (Yes) } \\
\text { Age of First Sexual Encounter }\end{array}$ & 226 & $90 \%$ \\
Less than 15 Years of Age & 68 & $31 \%$ \\
15-19 Years Old & 134 & $61 \%$ \\
20-25 Years of Age & 16 & $7 \%$ \\
Currently Having Sex (Yes) & 146 & $65 \%$ \\
Ever used Family Planning (Yes) & 162 & $72 \%$ \\
Where would go for Family Planning Services $(n=239)$ & \\
$\quad$ Hospital & 160 & $67 \%$ \\
Community Clinic & 58 & $24 \%$ \\
Village Health Team & 21 & $9 \%$ \\
\hline
\end{tabular}

hormonal contraceptives the second and third most frequently mentioned. Condom use was significantly higher among men and unmarried respondents. Other LAPMs such as intrauterine devices and implants were rarely mentioned. LAPMs use was particularly low in the youngest age group, who reported the highest proportion of injectable use and the lowest proportion of implant use.

Having had children and being sexually active were significantly and positively associated with ever having used FP when controlling for other socio-demographic factors: $\mathrm{AOR}=3.205$; $(95 \% \mathrm{CI}: 1.229,8.356)$ and $\mathrm{AOR}=$ 5.252 (95\%CI: $2.41,11.41$ ) respectively (see Table 4).

\section{Health seeking behavior and barriers to care}

Almost all respondents (96\%) said that they knew where they would seek FP services if they needed them. When questioned about whom they would ask if they had a question about family planning, most said they would seek a health professional (66\% overall, $60 \%$ in the youngest age group). The next most frequently mentioned potential sources of information were VHTs (27\%) and friends $(21 \%)$. There were no significant differences by age group or marital status in preferred sources of FP information.

Table 2 Sources of Family Planning Education Among Youth in Nakaseke District, Uganda

\begin{tabular}{lll}
\hline & Number $(\mathbf{n = 2 5 0 )}$ \\
\hline Ever Heard the Term "Family Planning" (Yes) & 236 \\
Ever Received FP Education (Yes) & 152 \\
Where Received FP Education $(n=152)$ & \\
Hospital & $94 \%$ \\
Community Clinic & $94 \%$ \\
Village Health Team & 15 \\
Other & 31 \\
\hline
\end{tabular}




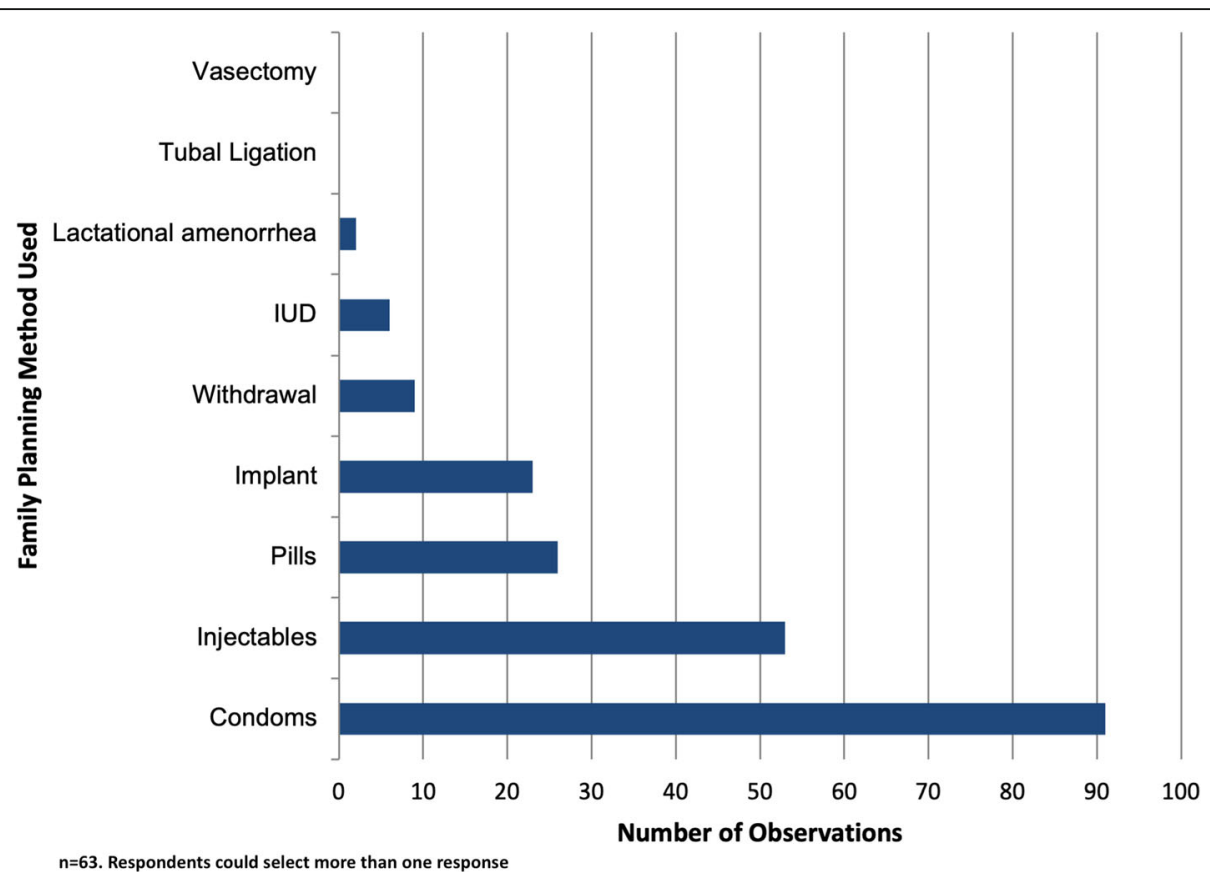

Fig. 1 Family Planning Methods Used by Youths in Nakaseke District, Uganda $(n=162) \neq$ Respondents could select more than one response

Barriers to accessing FP services identified in FGDs included lack of time, distance to services, and cost. In the survey, the most common reason for not using FP was concern about potential side effects (see Fig. 2). Participants in all three focus groups also reported concerns and misconceptions about potential side effects such as amenorrhea, congenital disabilities, and infertility. In focus groups, concerns about side effects were more pronounced among women than men.

"I used an injection before and spent a full year without getting my menses, but when they resumed, they were normal, but I fear to do the injection

Table 4 Logistic Regression: Factors Associated with Ever Using Family Planning $(n=221)^{\ddagger}$

\begin{tabular}{|c|c|c|}
\hline Factor & Adjusted Odds Ratio & 95\% Confidence Interval \\
\hline Female & 0.493 & {$[0.219,1.109]$} \\
\hline \multicolumn{3}{|l|}{ Age Group } \\
\hline Less than 18 Years Old & 0.726 & {$[0.273,1.929]$} \\
\hline 19-21 Years Old & 1.315 & {$[0.570,3.033]$} \\
\hline Older than 21 Years Old & Base & \\
\hline \multicolumn{3}{|l|}{ Educational Level } \\
\hline Primary & Base & \\
\hline Secondary & 1.848 & {$[0.877,3.892]$} \\
\hline Tertiary & No observation & \\
\hline None & 1.554 & {$[0.231,10.45]$} \\
\hline \multicolumn{3}{|l|}{ Marital Status } \\
\hline Single or Unmarried & Base & \\
\hline Married or Divorced & 0.405 & {$[0.151,1.082]$} \\
\hline Have had Children & $3.205^{*}$ & {$[1.229,8.356]$} \\
\hline Currently Having Sex & $5.252^{* * *}$ & {$[2.417,11.41]$} \\
\hline
\end{tabular}

${ }^{*} p<0.05$, ** $p<0.01,{ }^{* * *} p<0.001$

$\$ 29$ observations were dropped from the regression due to missing responses. 


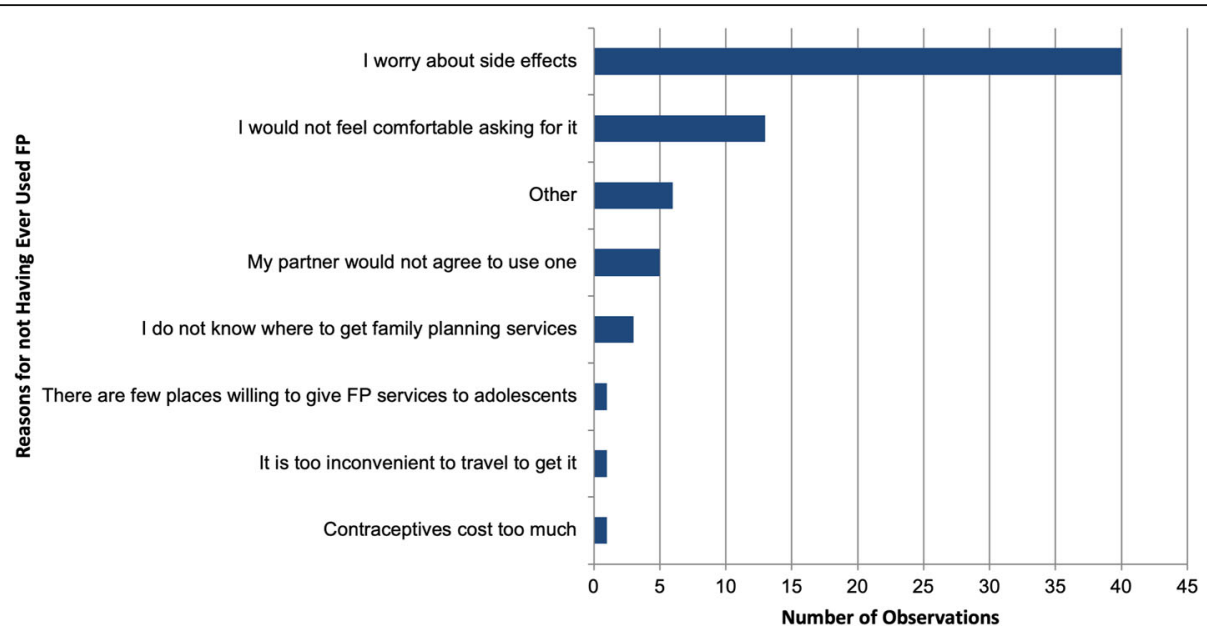

Fig. 2 Reasons for not Having Ever Used Family Planning Services in Nakaseke District, Uganda $(n=63)^{\ddagger}$. $\neq$ Respondents could select more than one response

again because I was told I would get fibroids or fail to conceive. That scared me." - (Female Respondent, FG2)

However, the most consistent theme, cited most frequently across all three groups when discussing barriers, was the stigma surrounding family planning services and the resulting fear and shame that accompanied attempts to access these services. For example, respondents often stated that the use of family planning services by unmarried women suggested promiscuity.

"If your parent finds out that you are on family planning, he/she would just know that you are sleeping around with men. Otherwise, why would you be on them? [...] They think you shouldn't be having sex at that time. So if you're not having sex, why would you go for family planning methods?" - (Female Respondent, FG1)

"Most people know (about family planning methods), but fear accessing them. For example, I cannot walk to a shop to buy a condom even if you gave me money to [because] people that see would think that you are going into a sexual act." - (Female Respondent, FG2)

While the theme of stigma among female respondents concerned stigma aimed at others and themselves, male respondents only discussed women being stigmatized for FP use. However, family planning services were deemed appropriate for married women, as this was associated with birth-spacing and was considered a decision to be made between a married couple.

"If you see a girl who is not married using that (long-term planning) method, you think that she is sleeping around with many men, but with a married woman that can't come to my mind because I know that it is between her and the husband." - (Male Respondent, FG3)

\section{Perceptions of VHTs}

VHTs were visible to the youth in our sample: $72 \%$ of respondents said they had seen a VHT working in their community, and $65 \%$ knew that VHTs provide free FP services. However, only half of the respondents had talked to a VHT and only $38 \%$ of those $\leq 18$ years of age. Most (84\%) said they would feel comfortable talking to a VHT about FP services (see Table 5).

When asked why they would not feel comfortable speaking to a VHT, the main reasons given were fear that VHTs would violate privacy (mentioned by $61 \%$ of those not comfortable), that VHTs would talk to parents (mentioned by 33\%), shyness (mentioned by 22 and $42 \%$ of those $\leq 18$ ), and fear of being judged (mentioned by $15 \%)$. The centrality of stigma and privacy concerns found in the survey data was echoed in all three focus groups (see Table 6).

Focus group participants consistently mentioned privacy concerns when discussing their willingness to use VHT services, specifically, the widely held belief that VHTs would gossip about their clients and "spread rumors." These confidentiality breaches were seen as particularly acute because they would occur in one's own 
Table 5 Perceptions of VHTs Among Youths in Nakaseke District, Uganda

\begin{tabular}{|c|c|c|}
\hline & Number $(n=250)$ & Percent \\
\hline Comfortable Talking to VHT about Health & 220 & $88 \%$ \\
\hline Comfortable Talking to VHT about Family Planning & 208 & $84 \%$ \\
\hline \multicolumn{3}{|l|}{ Reason for Potential Discomfort Talking to VHT about Family Planning ${ }^{\ddagger}$} \\
\hline I would be afraid the VHT would share our conversation with my parents & 55 & $33 \%$ \\
\hline There would be no privacy when talking to VHTs & 102 & $61 \%$ \\
\hline I would not want to reveal that I am having sex & 28 & $17 \%$ \\
\hline I would feel shy talking about sex & 37 & $22 \%$ \\
\hline I would be afraid that the VHT is judging me & 25 & $15 \%$ \\
\hline I would be afraid that the VHT would not treat me well & 12 & $7 \%$ \\
\hline Important that VHT is the Same Sex & 212 & $85 \%$ \\
\hline Important that VHT is the Same Age & 196 & $78 \%$ \\
\hline
\end{tabular}

‡Respondents could select more than one response

village. Participants often stated that a VHT from a different village, or VHTs who were older, might be relatively more trustworthy in keeping sensitive information private (see Table 6).

Privacy concerns were also central for deciding whether or not to use VHT services in the future. Survey respondents said the main factors for decision-making about using VHTs were whether privacy would be respected (mentioned by $45 \%$ of respondents), the proximity of care $(22 \%)$, and the respectfulness of care $(27 \%)$. There were no significant differences in deciding factors by age group, sex, or marital status. The cost of VHT care was not a significant concern for survey respondents (mentioned by only $8 \%$ ).

The privacy theme was related to a parallel theme concerning a desire for professionalism and solid training in FP service providers. For example, in the focus groups, respondents said they preferred formal, facility-based services to VHTs not only because of privacy concerns but also because of worries about VHT's capacity and ability to provide quality FP services. Several respondents believed that VHT capacities were limited to non-family planning services and that VHT service quality was questionable.

Table 6 Focus Group Themes of Privacy Concerns Regarding Use of VHTs

\begin{tabular}{|c|c|c|c|}
\hline & $\begin{array}{l}\text { Theme 1: Prefer someone from a different } \\
\text { village }\end{array}$ & Theme 2: VHTs gossip & $\begin{array}{l}\text { Theme 3: Young VHTs are not } \\
\text { preferred to older }\end{array}$ \\
\hline $\begin{array}{l}\text { Focus } \\
\text { Group \#1: } \\
\text { Mixed } \\
\text { Sexes }\end{array}$ & $\begin{array}{l}\text { Moderator: So you don't want a VHT to come to } \\
\text { your community and provide these services? } \\
\text { Respondent: No. Take you for example, you are } \\
\text { new to the village, you work and we know that } \\
\text { you will leave and that you are not going to } \\
\text { spread the rumors, then I go to you [to receive } \\
\text { services]. }\end{array}$ & $\begin{array}{l}\text { Respondent: VHTs, mostly those who work in } \\
\text { villages, after coming to understand you, they } \\
\text { will make sure to spread the rumor. }\end{array}$ & $\begin{array}{l}\text { Moderator 1: What if a VHT was } \\
\text { like somebody your age, would } \\
\text { that make it different? } \\
\text { Respondent: No, they would still } \\
\text { talk. Those are even worse. } \\
\text { Moderator: So it's better if they are } \\
\text { older? } \\
\text { Respondent: The older one will be } \\
\text { experienced in that field and will } \\
\text { not spread the rumor to our fellow } \\
\text { youth. }\end{array}$ \\
\hline $\begin{array}{l}\text { Focus } \\
\text { Group \#2: } \\
\text { Females } \\
\text { only }\end{array}$ & $\begin{array}{l}\text { Respondent: The one from your village will } \\
\text { spread rumors about you because they know } \\
\text { where your house is. }\end{array}$ & $\begin{array}{l}\text { Moderator 2: Don't you like VHTs? } \\
\text { Respondent: They spread rumors. }\end{array}$ & $\begin{array}{l}\text { Respondent: It can work for you if } \\
\text { you trusted that peer. } \\
\text { Moderator 1: So you don't want } \\
\text { to go see a VHT if they are older, } \\
\text { right? } \\
\text { Respondent: If you trust them...s/ } \\
\text { he is safe. }\end{array}$ \\
\hline $\begin{array}{l}\text { Focus } \\
\text { Group \#3: } \\
\text { Males } \\
\text { only }\end{array}$ & Not mentioned & $\begin{array}{l}\text { Moderator: So do you think the VHTs in your } \\
\text { community should be talking to boys in your } \\
\text { community about this kind of thing? } \\
\text { Respondent: They should be doing it but I } \\
\text { for myself I can't open up to him or her } \\
\text { because she might discuss about me with her } \\
\text { friends in the community. }\end{array}$ & $\begin{array}{l}\text { Respondent: No we can't open up } \\
\text { to our age mates. } \\
\text { Moderator: So it is better if they } \\
\text { are older? } \\
\text { Respondent: Yes. }\end{array}$ \\
\hline
\end{tabular}


"[VHT] services are known; mosquito nets, immunization of children. That is all they can handle: distribution of mosquito nets." - (Sex Unrecorded, FG1)

"You get better information at the clinic than from the peer VHTs." - (Female Respondent, FG2)

The only factor significantly associated with the level of comfort speaking to a VHT was educational level. Respondents with a tertiary level of education were much less likely to say that they were comfortable speaking to a VHT than those with a primary school education when controlling for other behavioral and demographic factors $(\mathrm{AOR}=0.056, \quad 95 \% \quad \mathrm{CI}$ : $0.011,0.294$ ) (see Table 7).

When we explored the importance of VHTs' sex and age in influencing the utilization of VHT services, we had mixed results. The majority of survey respondents $(85 \%)$ said having VHTs of similar sex was important to them, particularly those in the youngest age group ( $\mathrm{OR}=4.45,95 \% \mathrm{CI}: 1.24,16.00)$ and those who were single or unmarried $(\mathrm{OR}=5.02$, 95\% CI: 2.42, 10.39). Similarly, most survey respondents $(74 \%)$ also said that having VHTs of a similar age was important, and married respondents were significantly more likely to say so $(\mathrm{OR}=2.84,95 \%$ CI: 1.53, 5.29). However, several FGD participants preferred VHTs who were older than themselves because they viewed older VHTs as being more experienced, professional, and trustworthy.
"I can't talk with my age mate because in most cases if your age mate is advising you; you might not take it seriously. So it is better if the person is older than you. If this person gives you advice, you can easily take it on because of the respect you have for him." - (Male Respondent, FG3)

FGD participants also voiced differing, conflicting views on VHT sex preference. Some preferred same-sex VHTs; some female participants preferred male VHTs because they believed they would be less likely to gossip; and some male participants said they preferred female VHTs because they were more professional than male VHTs.

\section{Discussion}

This study set out to assess FP health-seeking behavior among youths in Nakaseke, Uganda, and their awareness, attitudes, and practices regarding VHT provision of FP services.

We found evidence of a significant unmet need for FP services in this sample. Most respondents were sexually active, and a significant proportion of those under 18 already had children. While $70 \%$ of youth aged 18 and under-reported having had sex, only 55\% reported having ever used family planning. This evidence of an unmet need for FP services echoes the findings of previous Ugandan studies [2, 13, 49]. It underscores the work that remains to be done to ensure access to, and utilization of, FP services among youth.

Several access and utilization barriers that VHTs should address, including time, cost, and distance to FP

Table 7 Logistic Regression: Factors Associated with Being Comfortable Talking to a VHT about Family Planning $(n=221) \neq$

\begin{tabular}{|c|c|c|}
\hline Factor & Adjusted Odds Ratio & 95\% Confidence Interval \\
\hline Female & 0.863 & {$[0.310,2.401]$} \\
\hline \multicolumn{3}{|l|}{ Age Group } \\
\hline Less than 18 Years Old & 1.194 & {$[0.294,4.858]$} \\
\hline 19-21 Years Old & 0.704 & {$[0.244,2.025]$} \\
\hline Older than 21 Years Old & Base & \\
\hline \multicolumn{3}{|l|}{ Educational Level } \\
\hline Primary & Base & \\
\hline Secondary & 0.395 & {$[0.136,1.149]$} \\
\hline Tertiary & $0.056^{* * *}$ & {$[0.011,0.294]$} \\
\hline None & 0.41 & {$[0.040,4.216]$} \\
\hline \multicolumn{3}{|l|}{ Marital Status } \\
\hline Single or Unmarried & Base & \\
\hline Married or Divorced & 0.833 & {$[0.275,2.522]$} \\
\hline Have had Children & 1.407 & {$[0.457,4.337]$} \\
\hline Currently Having Sex & 1.848 & {$[0.752,4.544]$} \\
\hline
\end{tabular}

* $\mathrm{p}<0.05,{ }^{* *} \mathrm{p}<0.01,{ }^{* * *} \mathrm{p}<0.001$

$\neq 29$ observations were dropped from the regression due to missing responses. 
services, were still frequently mentioned as barriers to care in this community where VHTs are active. However, the most frequently mentioned reason for not using FP was concern about side effects, particularly from LAPMs. Several sub-Saharan African studies have found that concerns about side effects and misconceptions about the effects of long-term contraceptive use are common [50-54]. While these misconceptions and concerns are not uniquely found in VHT-based FP programs, the presence of VHTs in the study communities has not been sufficient to dispel them. Together the persistence of access barriers and misconceptions regarding contraceptive side effects reflect the finding that youth are not utilizing VHT services.

Overall, we found high awareness of VHTs services but little prior use and low willingness to use these services in the future. Despite the presence of VHTs in their communities, only half of the youth surveyed had ever talked to a VHT. When asked about FP education sources, only $20 \%$ mentioned VHTs as a source; however, we note that this low estimate could be an artifact of the survey instrument that did not allow respondents to select multiple FP education sources. Nevertheless, even though most survey respondents (84\%) said that they would feel comfortable talking to a VHT about family planning, when asked where they would seek FP information if they needed it, only $9 \%$ mentioned a VHT as their first choice.

When we asked youth about their reasons for nonutilization of VHTs, we found that worries about privacy and confidentiality were the primary drivers of reluctance. Both survey and focus group respondents indicated that they were worried that VHTs would gossip or otherwise share information and that this would reveal their sexual activity to parents and might paint them as promiscuous in their peers' eyes. Internalized stigma and the related privacy concerns are commonly cited as reasons for low use of facility-based FP service among adults and youth in sub-Saharan Africa $[11,55,56]$, and privacy and confidentiality protections are frequently used as an indicator of the "youth friendliness" of facility-based services [57]. However, our findings suggest that these privacy concerns may be particularly acute for community-based FP programs that use CHWs such as Uganda's VHTs.

Previous studies of HIV/AIDS and maternal and child health programs that use CHWs have found that community members worry about sharing information with CHWs because CHWs are seen as members of the community who are likely to pass on private information to peers and neighbors $[58,59]$. Lack of trust of CHWs and fear of confidentiality breaches have been cited in many other CHW health programs and have been identified as reasons for low acceptance of $\mathrm{CHW}$ services [58]. These studies, like ours, find that community members may prefer to speak about sensitive matters to providers who live outside of the community and to those in formal health facilities, because these providers are seen as being more likely to protect confidentiality due to their distance, their professional codes of conduct, and their more extensive training [59].

Our respondents seemed not only to fear having sensitive information shared with the community, but also to fear judgment from VHTs themselves. Approximately $15 \%$ of respondents cited a fear of judgment as the reason for discomfort in talking to VHTs; and 7\% said that they would fear that a VHT would not treat them well. This fear may be justified, as previous studies in Uganda have found that providers can be disapproving of adolescents engaging in premarital sex and are often reluctant to give adolescents a full range of family planning services [60].

Overall, prior studies and ours suggest that the main strength of CHWs-their rootedness in their communities and its norms-may also make community members reluctant to talk to them about stigmatized or socially sanctioned behavior such as premarital sex among adolescents. Several studies have documented that $\mathrm{CHW}$ attitudes and beliefs may reflect conservative norms that are prevalent in their communities and that CHWs are often embedded in local power structures [58, 61-65], and provider bias has been documented as a critical factor affecting the uptake of contraceptive services, especially among adolescent, unmarried, or nulliparous women in other studies in sub-Saharan Africa $[66,67]$. In these studies, parity and marriage are often positively associated with modern family planning use [66], which is consistent with our findings that married youth face less stigma in using FP services, as family planning decisions are seen as marital decisions. Youths' awareness of possible provider bias may partially explain the reluctance to utilize VHT FP services found in our study.

One proposed means of increasing provider trust in services targeted at youth has been using peer-providers of similar age and sex. While studies have found that having CHWs of the same sex as clients increased uptake of services [61], our study finds mixed support for this intervention. Most survey respondents said that having VHTs of similar age and sex was desirable, and having VHTs of the same sex was particularly important for younger respondents. However, many focus group participants (who were older than survey respondents) preferred VHTs who were older than them because they viewed older VHTs as more professional. Several said that they preferred providers of the opposite sex. Female focus group respondents believed that male VHTs would be more likely to keep conversations private, while some male focus group respondents thought female VHTs 
would be more professional. Overall, our data suggest that preference for similar sex VHTs was not unanimous and, along with age matching, may be a more important consideration for younger clients rather than older youth.

Focus group responses to questions about age and sex matching highlight another theme found in provider choice discussions, namely the importance of quality of care. Preferences for a particular sex of VHT were driven not by which sex would be the most sympathetic or relatable but rather by which was seen as being the most professional. Similarly, the main reason for not preferring VHTs of similar age was concern that younger VHTs would not be as professional and knowledgeable as older VHTs. We also see in the focus groups that VHTs may be viewed as having a limited range of knowledge and skills and that this may influence decisions about whether to use their services. Quality concerns may be more pronounced among older, married, and better-educated youth, as indicated in our finding that higher education levels were associated with lower comfort using VHT services. It could be that more educated youth perceive VHTs as providing lower-quality care reserved for lowerstatus community members.

Despite the concerns that this study has raised about the use of CHWs to provide FP services to youth, the CHW model still has promising potential to increase access to FP services for older community members. A systematic review of 56 studies of CHW FP programs reported that $93 \%$ of studies found that CHW FP programs effectively increase the use of modern contraception, while $83 \%$ reported an improvement in knowledge and attitudes concerning contraceptives [34]. In addition, several studies have found that $\mathrm{CHW}$ s can improve health outcomes for HIV/AIDS and maternal and child health programs $[68,69]$. Based on these findings, strong evidence exists for promoting CHW programs to improve access to FP services overall. However, the literature also suggests that there is an ongoing need to monitor and address quality of care and confidentiality concerns in CHW programs [34].

\section{Programmatic implications}

VHT messaging and training should focus on protecting privacy during conversations and the confidentiality of information shared during these conversations to alleviate privacy and quality concerns. More attention should also be paid to providing respectful care and addressing concerns and misconceptions about contraceptive side effects. The training that VHTs receive, the range of services they provide, and qualifications that they have should be more widely discussed in health outreach activities in order to allay concerns about the quality of care they provide and to promote an image of them as professionals. More stringent screening in selecting VHTs may also be required to recruit VHTs who are open to providing services to youth.

Greater professionalization of VHTs, including more standardized training, more consistent remuneration, and greater integration with health facility outreach efforts, might improve the delivery of care, increase trust in VHTs, and improve perceptions of their competence. More rigorous professional training and better remuneration have long been VHT requests [63]. Countries such as Ethiopia that have fully incorporated CHWs into their formal national health programs with standardized training, scopes of work, and remuneration have seen increased utilization of CHWs and improved perceptions of health service capacity [70-72]. However, increased professionalization of CHWs might also reduce their ability to counsel clients. Trust between CHWs and their clients often rests on the perception of CHWs as peers rather than external health professionals. CHWs frequently use this insider status and community membership to facilitate discussions of sensitive issues [63]. Some stakeholders fear that professionalization that requires additional training and the use of scripts and protocols would change CHWs' educational and social status and their perceived allegiances to formal government structures, which could, in turn, decrease community trust in their services $[73,74]$.

In addition to changes in the training, remuneration, screening, and outreach messages of VHTs, the utilization of tools to structure patient interactions such as mobile job aids to support counseling could improve VHTs' communication with clients and the quality of care provided, thereby improving trust [75-77]. Mobile phone applications could help VHTs adhere to service delivery protocols and improve community confidence in their competence. Such applications have been widely used in FP, HIV, and maternal and child health programs [78].

When targeting adolescents in the youngest age group, younger VHTs of appropriate sex should be hired to encourage youth service utilization. More positive and creative messaging and outreach from VHTs are also needed to reassure this youngest age-group that services will be provided without judgment and to reduce the stigma associated with these services. Integrating VHT's FP outreach into ongoing health promotion campaigns, such as vaccination drives and micro-nutrient supplementation campaigns, might increase the number of socially acceptable venues at which adolescents can interact with VHTs and receive FP counseling. VHT partnerships with existing SRH peer-education initiatives and informal health care settings such as drug shops might also help in this regard. For example, where they exist, peer educators could link youth in need of services to VHTs, and VHTs could assist in training peer educators on different FP methods. 


\section{Strengths and limitations}

This study has several strengths and limitations. It is one of the few studies of community-based family planning programs to seek youths' views on the role of VHTs in the provision of family planning services. Also, it uses both qualitative and quantitative data to gain a deeper understanding of their health-seeking behavior than could be obtained by either approach alone. Finally, it examines youth interactions with VHTs in a setting where VHTs have been actively providing family planning services for several years. However, this study is conducted in a single district in Uganda, limiting its generalizability to the rest of the country and the region. The focus groups were small in size and number, which did not allow us to explore in-depth how themes varied across demographic groups. The wording of several of our survey items may have limited respondents' ability to tell us their sources of FP education and services. For example, drug shops were not included as an FP service source, and respondents could only list one source of past FP education. Additionally, data collection was conducted by staff associated with ACCESS, an organization well known in the study area; this may have led to social desirability bias in responses. If social desirability bias was a significant factor, it would suggest that VHT use and rates of reported comfort are inflated in our findings and may, in truth, be lower than reported.

Only a quarter of our survey respondents were male, and only $39 \%$ of all respondents were adolescents (between ages 10-19). Adolescents may be less comfortable talking to VHTs about family planning than older youth due to stigma, particularly in a predominantly Catholic area such as Nakaseke. This further suggests that our estimates of VHT use might be inflated.

\section{Conclusions}

Our study finds that VHTs are a known source of FP services among older youth in Nakaseke District, but are not widely used, due primarily to privacy concerns surrounding the use of stigmatized FP services. Our findings also suggest that the perceived trustworthiness and competence of VHTs of similar age and sex may vary by age group. Further studies to compare preferences for peer VHTs in different youth age groups may be needed to guide the recruitment and training of VHTs for community-based FP programs in Uganda.

\section{Abbreviations}

ACCESS: African Community Center for Social Sustainability;

CHW: Community health worker; (U)DHS: (Ugandan) Demographic and Health Surveys; FP: Family planning; HIV/AIDS: Human immunodeficiency virus, acquired immunodeficiency syndrome; LAPM: Long-acting and permanent methods; SRH: Sexual and reproductive health; VHT: Village Health Team

\section{Supplementary Information}

The online version contains supplementary material available at https://doi. org/10.1186/s12889-021-10695-y.

Additional file 1 Appendix A Data collection instruments. The data collection tool contains the questionnaire and the guidelines for the focus group discussions (FGD)

\section{Acknowledgments}

We would like to acknowledge the hard work and professionalism of our data collectors. We are also grateful for the input that Dr. Sarah Jane Holcombe provided in developing our data collection tools.

\section{Authors' contributions}

RK, SY, SB, RM, and JM conceptualized the study. JA, RM, IW, JM, and FN coordinated data collection. SB, MT, and JMP analyzed the data. JMP and SB led initial manuscript development with RK, JM, RM, and IW contributing to subsequent drafts. All authors read and approved the final manuscript.

\section{Funding}

This study was funded by a grant from Robert K. Pedersen Global Outreach Endowment. The ACCESS-Uganda Family Planning among Rural Communities of Nakaseke through Multi-skilled Community Health Worker Training and Mobilization Project was supported by a generous grant from Edith $\mathrm{H}$. and Eric E. Bergstrom Foundation. The study and project sponsors had no involvement in the study.

\section{Availability of data and materials}

The datasets generated and analyzed during the current study are not publicly available due to a lack of Institutional Review Board authorization for public posting of data. However, they are available from the corresponding author on reasonable request. Data requests can be sent to Robert Kalyesubula (rkalyesubula@gmail.com).

\section{Declarations}

Ethics approval and consent to participate

The study was approved by the Institutional Review Boards at Touro University California (\#PH-0518), and the Mulago Hospital Research and Ethics Committee (\#1583). All participants were told the aims of the study, that their participation was voluntary, and that they could withdraw participation at any time without consequences. In addition, written consent or assent for participation was obtained from all participants. Parental permission was also obtained for all respondents under the age of 18 . The procedure for obtaining permission from parents and guardians for minors who aggreged to participate in the study was approved by the Institutional Review Boards/Ethics review committees that reviewed the study protocol.

\section{Consent for publication}

Not applicable.

\section{Competing interests}

The authors declare that they have no competing interests.

\section{Author details}

${ }^{1}$ African Community Center for Social Sustainability, Nakaseke, Uganda. ${ }^{2}$ Makerere University College of Health Sciences, Kampala, Uganda. ${ }^{3}$ Touro University California, California, USA.

Received: 2 July 2020 Accepted: 23 March 2021

Published online: 07 April 2021

\section{References}

1. Uganda Bureau of Statistics (UBOS) and ICF. Uganda demographic and health survey 2016 [internet]. Kampala, Uganda and Rockville, Maryland: UBOS and ICF; 2018. Available from: https://dhsprogram.com/pubs/pdf/ FR333/FR333.pdf

2. In Uganda, Sexual and Reproductive Health Services and Information Fall Short for Adolescents [Internet]. Guttmacher Inst. 2019 [cited 2020 Apr 16]. 
Available from: https://www.guttmacher.org/news-release/2019/ugandasexual-and-reproductive-health-services-and-information-fall-short

3. Filippi V, Chou D, Ronsmans C, Graham W, Say L. Levels and Causes of Maternal Mortality and Morbidity. In: Black RE, Laxminarayan R, Temmerman M, Walker N, editors. Reprod Matern Newborn Child Health Dis Control Priorities Third Ed Vol 2 [Internet]. Washington (DC): The International Bank for Reconstruction and Development / The World Bank; 2016 [cited 2020 Apr 17]. Available from: http://www.ncbi.nlm.nih.gov/books/NBK361917/

4. Ganchimeg T, Ota E, Morisaki N, Laopaiboon M, Lumbiganon P, Zhang J, et al. Pregnancy and childbirth outcomes among adolescent mothers: a World Health Organization multicountry study. BJOG Int J Obstet Gynaecol. 2014;121(Suppl 1):40-8. https://doi.org/10.1111/1471-0528.12630.

5. Ahinkorah BO, Hagan JE, Seidu A-A, Budu E, Hormenu T, Mintah JK, et al. Access to Adolescent Pregnancy Prevention Information and Services in Ghana: A Community-Based Case-Control Study. Front Public Health [Internet]. 2019 [cited 2020 Apr 7];7. Available from: https://www.ncbi.nlm. nih.gov/pmc/articles/PMC6927296/

6. McCarthy DU. The Timing of a First Birth and High School Completion. RTI International. P.O. Box 12194, Research Triangle Park, NC 27709-2194. Tel: 919-541-6000; e-mail: publications@rit.org; Web site: http://www.rti.org; 1990 [cited 2020 Apr 17]; Available from: https://www.rti.org/publication/timingfirst-birth-and-high-school-completion

7. Breuner CC, Mattson G, Adolescence CO, Health C on PA of C and F. Sexuality Education for Children and Adolescents. Pediatrics [Internet]. American Academy of Pediatrics; 2016 [cited 2020 Apr 17];138. Available from: https://pediatrics.aappublications.org/content/138/2/e20161348

8. Fuzzell L, Shields CG, Alexander SC, Fortenberry JD. Physicians talking about sex, sexuality, and protection with adolescents. J Adolesc Health. Elsevier. 2017;61(1):6-23. https://doi.org/10.1016/j.jadohealth.2017.01.017.

9. Salam RA, Faqqah A, Sajjad N, Lassi ZS, Das JK, Kaufman M, et al. Improving adolescent sexual and reproductive health: a systematic review of potential interventions. J Adolesc Health Elsevier. 2016;59(4):S11-28. https://doi.org/1 0.1016/j.jadohealth.2016.05.022.

10. Starrs AM, Ezeh AC, Barker G, Basu A, Bertrand JT, Blum R, et al. Accelerate progress - sexual and reproductive health and rights for all: report of the Guttmacher-lancet commission. The Lancet Elsevier. 2018;391(10140):264292. https://doi.org/10.1016/S0140-6736(18)30293-9.

11. Silumbwe A, Nkole T, Munakampe MN, Milford C, Cordero JP, Kriel Y, et al. Community and health systems barriers and enablers to family planning and contraceptive services provision and use in Kabwe District, Zambia. BMC Health Serv Res. 2018;18(1):390. https://doi.org/1 0.1186/s12913-018-3136-4

12. Biddlecom AE, Munthali A, Singh S, Woog V. Adolescents' views of and preferences for sexual and reproductive health services in Burkina Faso, Ghana, Malawi and Uganda. Afr J Reprod Health. 2007;11(3):99-100. https:// doi.org/10.2307/25549734.

13. Nalwadda G, Mirembe F, Byamugisha J, Faxelid E. Persistent high fertility in Uganda: young people recount obstacles and enabling factors to use of contraceptives. BMC Public Health. 2010;10(1):530. https://doi.org/10.1186/14 71-2458-10-530.

14. WHO | National age-of-consent laws and adolescent HIV testing in subSaharan Africa: a propensity-score matched study [Internet]. WHO. World Health Organization; [cited 2020 Apr 17]. Available from: http://www.who. int/bulletin/volumes/97/1/18-212993/en/

15. Sidze EM, Lardoux S, Speizer IS, Faye CM, Mutua MM, Badji F. Young Women's access to and use of contraceptives: the role of providers' restrictions in urban Senegal. Int Perspect Sex Reprod Health. 2014;40(04): 176-83. https://doi.org/10.1363/4017614.

16. Appiah SCY. Youth friendliness of sexual and reproductive health service delivery and reproductive health service utilization in Ghana. Int J Innov Appl Stud. 2015;10:716-25.

17. Neema S, Musisi N, Kibombo R. Adolescent sexual and reproductive health in Uganda: a synthesis of research evidence. New York: Alan Guttmacher Institute; 2004

18. Moore AM, Awusabo-Asare K, Madise N, John-Langba J, Kumi-Kyereme A. Coerced first sex among adolescent girls in sub-Saharan Africa: prevalence and context. Afr J Reprod Health. 2007;11(3):62-82. https://doi.org/10.2307/2 5549732.

19. Wagman J, Baumgartner JN, Waszak Geary C, Nakyanjo N, Ddaaki WG, Serwadda D, et al. Experiences of sexual coercion among adolescent women: qualitative findings from Rakai District, Uganda. J Interpers Violence
SAGE Publications Inc. 2009;24(12):2073-95. https://doi.org/10.1177/08862 60508327707.

20. Maxwell L, Devries K, Zionts D, Alhusen JL, Campbell J. Estimating the Effect of Intimate Partner Violence on Women's Use of Contraception: A Systematic Review and Meta-Analysis. PLOS ONE. Public Library of Science. 2015;10:e0118234.

21. Kusunoki Y, Barber JS, Gatny HH, Melendez R. Physical Intimate Partner Violence and Contraceptive Behaviors Among Young Women. J Womens Health. Mary Ann Liebert, Inc., publishers. 2017;27:1016-25.

22. Cha S, Chapman DA, Wan W, Burton CW, Masho SW. Intimate partner violence and postpartum contraceptive use: the role of race/ethnicity and prenatal birth control counseling. Contraception Elsevier. 2015;92(3):268-75. https://doi.org/10.1016/j.contraception.2015.04.009.

23. Silverman JG, Boyce SC, Dehingia N, Rao N, Chandurkar D, Nanda P, et al. Reproductive coercion in Uttar Pradesh, India: Prevalence and associations with partner violence and reproductive health SSM. Popul Health. 2019;9: 100484.

24. Alli F, Maharaj P, Vawda M. Interpersonal relations between health care workers and young clients: barriers to accessing sexual and reproductive health care. J Community Health. 2012;38.

25. Hoopes A, Benson S, Howard H, Morrison D, Ko L, Shafii T. Adolescent perspectives on patient-provider sexual health communication: a qualitative study. J Prim Care Community Health. 2017;8:215013191773021.

26. Michaels-Igbokwe C, Terris-Prestholt $F$, Lagarde M, Chipeta E. Initiative the I, Cairns I Young People's Preferences for Family Planning Service Providers in Rural Malawi: A Discrete Choice Experiment. PLOS ONE. 2015;10:e0143287.

27. Erulkar AS, Onoka CJ, Phiri A. What is youth-friendly? Adolescents' Preferences for Reproductive Health Services in Kenya and Zimbabwe. Afr J Reprod Health. 2005;9:51.

28. World Health Organization. WHO recommendations on adolescent sexual and reproductive health and rights [Internet]. Geneva: World Health Organization; 2018 [cited 2021 Feb 12]. Available from: https:/apps.who.int/ iris/bitstream/handle/10665/275374/9789241514606-eng.pdf?ua=1

29. United Nations Population Fund. Choices not Chance: UNFPA Family Planning Strategy 2012-2020, vol. 2013. New York, NY: United Nations Population Fund. p. 44.

30. Mandira P, Chalasani BL, Knutsson A, Fatusi A. Contraception for Adolescents and Youth: Being responsive to their sexual and reproductive health needs and rights [Internet]. United Nations Population Fund; 2019 Nov p 24. Available from: https://www.unfpa.org/sites/default/files/resourcepdf/AY_Contraception_11Nov_UnfpaFonts_v2.pdf

31. Family Planning High Impact Practices. Adolescent-friendly contraceptive services: mainstreaming adolescent-friendly elements into existing contraceptive services [internet]. Washington, DC: United States Agency for International Development; 2015. Available from: https://www.fphighimpa ctpractices.org/briefs/adolescent-friendly-contraceptive-services/

32. Education ministry approves sexuality education framework [Internet]. Dly. Monit. [cited 2020 Apr 16]. Available from: https://www.monitor.co.ug/ News/National/Education-ministry-approves-sexuality-education-framework/ 688334-4356722-w39aflz/index.html

33. Darabi L, Bankole A, Serumaga K, Neema S, Kibombo R, Ahmed H, et al. Protecting the next generation in Uganda: new evidence on adolescent sexual and reproductive health needs. New York: Guttmacher Institute; 2008. p. 52

34. Scott VK, Gottschalk LB, Wright KQ, Twose C, Bohren MA, Schmitt ME, et al. Community health workers' provision of family planning Services in low- and Middle-Income Countries: a systematic review of effectiveness. Stud Fam Plan. 2015;46(3):241-61. https://doi.org/10.1111/ j.1728-4465.2015.00028.x.

35. Sedlander E, Bingenheimer JB, Edberg MC, Rimal RN, Shaikh H, Munar W. Understanding modern contraception uptake in one Ethiopian community: a case study. Reprod Health [Internet]. 2018 [cited 2020 Apr 16];15. Available from: https://www.ncbi.nlm.nih.gov/pmc/articles/PMC6011588/

36. Mazzei A, Ingabire R, Mukamuyango J, Nyombayire J, Sinabamenye R, Bayingana $R$, et al. Community health worker promotions increase uptake of long-acting reversible contraception in Rwanda. Reprod Health. 2019;16(1): 75. https://doi.org/10.1186/s12978-019-0739-0.

37. Lutalo T, Kigozi G, Kimera E, Serwadda D, Wawer MJ, Zabin LS, et al. A randomized community trial of enhanced family planning outreach in Rakai, Uganda. Stud Fam Plann. 2010;41(1):55-60. https://doi.org/10.1111/j.1728-44 65.2010.00224.x 
38. Brooks MI, Johns NE, Quinn AK, Boyce SC, Fatouma IA, Oumarou AO, et al. Can community health workers increase modern contraceptive use among young married women? A cross-sectional study in rural Niger. Reprod Health. 2019;16:38

39. Katz KR, West CG, Doumbia F, Kane F. Increasing access to family planning Services in Rural Mali through Community-Based Distribution. Int Fam Plan Perspect Guttmacher Institute. 1998;24(3):104-10. https://doi.org/10.2307/3038206.

40. Ministry of Health, Uganda. Village Health Team Strategy and Operational Guidelines [Internet]. Kampala, Uganda; 2020 Mar. Available from: http://libra ry.health.go.ug/publications/health-education/village-health-team-strategy-a nd-operational-guidelines

41. Ministry of Health, Uganda. Ministry of Health, Uganda. Uganda Family Planning Costed Implementation Plan, 2015-2020 [Internet]. Kampala, Uganda: Ministry of Health, Uganda; 2014. Available from: https://www.hea Ithpolicyproject.com/ns/docs/CIP_Uganda.pdf

42. Ministry of Health, Uganda. Policy Guidelines and Service Delivery Standards for Community-based Provision of Injectable Contraception in Uganda: Addendum to Uganda National Policy Guidelines and Service Standards for Sexual and Reproductive Health [Internet]. 2010 Dec. Available from: https:// toolkits.knowledgesuccess.org/sites/default/files/Uganda_CBD_Guidelines_ signed_0.pdf

43. Uganda Bureau of Statistics. The National Population and housing census 2014 - Main report [internet]. Kampala, Uganda: Uganda Bureau of Statistics; 2016. Available from: https://www.ubos.org/wp-content/uploads/ publications/03_20182014_National_Census_Main_Report.pdf

44. Department of Relief, Disaster Preparedness and Management. Nakaseke District Hazard, Risk and Vulnerability Profile [Internet]. Kampala, Uganda: Office of the Prime Minister; Available from: https://www.necoc-opm.go.ug/ HzCentral/Nakaseke\%20District\%20HRV\%20Profile.pdf

45. Cleland J, Ingham R, Stone N. Asking young people about sexual and reproductive behaviours: Illustrative Core Instruments. World Health Organization. 2005. https://www.gov.uk/research-for-development-outputs/a sking-young-people-about-sexual-and-reproductive-behaviours-illustrativecore-instruments. Accessed 30 Mar 2021.

46. AMN R, Kamara JK, Georgeou N, Kamanga G. Sexual, Reproductive Health Needs, and Rights of Young People in Slum Areas of Kampala, Uganda: A Cross Sectional Study. PLOS ONE. Public Library of Science. 2017;12:e0169721.

47. Mehra D, Agardh A, Petterson KO, Östergren P-O. Non-use of contraception: determinants among Ugandan university students. Glob Health Action. 2012:5:18599.

48. Kinaro J, Kimani M, Ikamari L, Ayiemba E. Perceptions and Barriers to Contraceptive Use among Adolescents Aged 15-19 Years in Kenya: A Case Study of Nairobi. Health (N Y). 2015;07:85-97.

49. Tsui AO, McDonald-Mosley R, Burke AE. Family planning and the burden of unintended pregnancies. Epidemiol Rev. 2010;32(1):152-74. https://doi.org/1 0.1093/epirev/mxq012.

50. Anguzu R, Tweheyo R, Sekandi JN, Zalwango V, Muhumuza C, Tusiime S, et al. Knowledge and attitudes towards use of long acting reversible contraceptives among women of reproductive age in Lubaga division, Kampala district, Uganda. BMC Res Notes. 2014;7(1):153. https://doi.org/1 0.1186/1756-0500-7-153.

51. Taye A, Woldie M, Sinaga M. Predictors of Long Acting Reversible Contraceptive use among Married Women Visiting Health Facilities in Jimma Town. J Womens Health Care [Internet]. 2015 [cited 2020 May 12];04. Available from: http://www.omicsgroup.org/journals/predictors-of-long-a cting-reversible-contraceptive-use-among-married-women-visiting-health-fa cilities-in-jimma-town-2167-0420.1000217.php?aid=36485

52. Wado YD, Gurmu E, Tilahun T, Bangha M. Contextual influences on the choice of long-acting reversible and permanent contraception in Ethiopia: A multilevel analysis. PLoS ONE [Internet]. 2019 [cited 2020 May 12];14. Available from: https://www.ncbi.nlm.nih.gov/pmc/articles/PMC6334991/

53. Moodley A, Mahomed O. Prevalence and predictors of Implanon uptake in Ugu (Ugu north Sub District) 2016/17. South Afr Fam Pract Taylor \& Francis. 2019:61(2):48-52. https://doi.org/10.1080/20786190.2018.1548725.

54. Okanlawon K, Reeves M, Agbaje Of. Contraceptive use: knowledge, perceptions and attitudes of refugee youths in Oru refugee camp, Nigeria Afr J Reprod Health 2010;14:16-25, 4 Spec no..

55. Atchison CJ, Cresswell JA, Kapiga S, Nsanya MK, Crawford EE, Mussa M, et al. Sexuality, fertility and family planning characteristics of married women aged 15 to 19 years in Ethiopia, Nigeria and Tanzania: a comparative analysis of cross-sectional data. Reprod Health. 2019;16:6.
56. Barden-O'Fallon J, Evans S, Thakwalakwa C, Alfonso W, Jackson A. Evaluation of mainstreaming youth-friendly health in private clinics in Malawi. BMC Health Serv Res [Internet]. 2020 [cited 2020 Jun 25];20. Available from: https://www.ncbi.nlm.nih.gov/pmc/articles/PMC6998314/

57. Mazur A, Brindis CD, Decker MJ. Assessing youth-friendly sexual and reproductive health services: a systematic review. BMC Health Serv Res. 2018;18(1):216. https://doi.org/10.1186/s12913-018-2982-4.

58. Grant M, Wilford A, Haskins L, Phakathi S, Mntambo N, Horwood CM. Trust of community health workers influences the acceptance of communitybased maternal and child health services. Afr J Prim Health Care Fam Med [Internet]. 2017 [cited 2020 Apr 20];9. Available from: https://www.ncbi.nlm. nih.gov/pmc/articles/PMC5458568/

59. Geldsetzer P, Vaikath M, De Neve J-W, Bossert TJ, Sibandze S, Mkhwanazi M, et al. Distrusting community health workers with confidential health information: a convergent mixed-methods study in Swaziland. Health Policy Plan. 2017;32(6):882-9. https://doi.org/10.1093/heapol/czx036.

60. Cover J, Namagembe A, Tumusiime J, Lim J, Cox CM. Ugandan providers' views on the acceptability of contraceptive self-injection for adolescents: a qualitative study. Reprod Health. 2018;15(1):165. https://doi.org/10.1186/s12 978-018-0611-7.

61. Kok MC, Kane SS, Tulloch O, Ormel H, Theobald S, Dieleman M, et al. How does context influence performance of community health workers in lowand middle-income countries? Evidence from the literature. Health Res Policy Syst [Internet]. 2015 [cited 2020 Apr 20];13. Available from: https:// www.ncbi.nlm.nih.gov/pmc/articles/PMC4358881/

62. Zulu JM, Kinsman J, Hurtig A-K, Michelo C, George A, Schneider H. Integrating community health assistant-driven sexual and reproductive health services in the community health system in Nyimba district in Zambia: mapping key actors, points of integration, and conditions shaping the process. Reprod Health [Internet]. 2019 [cited 2020 Apr 16];16. Available from: https://reproductive-health-journal.biomedcentral.com/articles/10.11 86/s12978-019-0788-4

63. Perry S, Fair C, Burrowes S, Holcombe SJ, Kalyesubula R. Outsiders, insiders, and intermediaries: village health teams' negotiation of roles to provide high quality sexual, reproductive and HIV care in Nakaseke, Uganda. BMC Health Serv Res [Internet]. 2019 [cited 2020 Apr 16];19. Available from: https://link.springer.com/article/10.1186/s12913-019-4395-4

64. Mlotshwa L, Harris B, Schneider H, Moshabela M. Exploring the perceptions and experiences of community health workers using role identity theory. Glob Health Action. 2015;8(1):28045. https://doi.org/10.3402/gha.v8.28045.

65. Schneider H, Lehmann U. From community health workers to community health systems: time to widen the horizon? Health Syst Reform Taylor \& Francis. 2016;2(2):112-8. https://doi.org/10.1080/23288604.2016.1166307.

66. Boydell V, Nulu N, Hardee K, Gay J. Implementing social accountability for contraceptive services: lessons from Uganda. BMC Women's Health. 2020;20: 228.

67. Nalwadda G, Tumwesigye NM, Faxelid E, Byamugisha J, Mirembe F. Quality of Care in Contraceptive Services Provided to Young People in Two Ugandan Districts: A Simulated Client Study. PLOS ONE. Public Libr Sci. 2011;6:e27908.

68. Mwai GW, Mburu G, Torpey K, Frost P, Ford N, Seeley J. Role and outcomes of community health workers in HIV care in sub-Saharan Africa: a systematic review. J Int AIDS Soc [Internet]. 2013 [cited 2020 Apr 20];16. Available from: https://www.ncbi.nlm.nih.gov/pmc/articles/PMC3772323/

69. Haines A, Sanders D, Lehmann U, Rowe AK, Lawn JE, Jan S, et al. Achieving child survival goals: potential contribution of community health workers. Lancet. Elsevier. 2007;369(9579):2121-31. https://doi.org/10.1016/S0140-673 6(07)60325-0.

70. Zulu JM, Kinsman J, Michelo C, Hurtig A-K. Integrating national community-based health worker programmes into health systems: a systematic review identifying lessons learned from low-and middleincome countries. BMC Public Health. 2014;14(1):987. https://doi.org/1 0.1186/1471-2458-14-987.

71. Singh D, Negin J, Otim M, Orach CG, Cumming R. The effect of payment and incentives on motivation and focus of community health workers: five case studies from low- and middle-income countries. Hum Resour Health. 2015;13(1):58. https://doi.org/10.1186/s12960-015-0051-1.

72. Assefa Y, Gelaw YA, Hill PS, Taye BW, Van Damme W. Community health extension program of Ethiopia, 2003-2018: successes and challenges toward universal coverage for primary healthcare services. Glob Health. 2019;15(1):24. https://doi.org/10.1186/s12992-019-0470-1. 
73. Turinawe EB, Rwemisisi JT, Musinguzi LK, de Groot M, Muhangi D, de Vries DH, et al. Selection and performance of village health teams (VHTs) in Uganda: lessons from the natural helper model of health promotion. Hum Resour Health. 2015;13(1):73. https://doi.org/10.1186/ s12960-015-0074-7.

74. Mays DC, O'Neil EJ, Mworozi EA, Lough BJ, Tabb ZJ, Whitlock AE, et al. Supporting and retaining village health teams: an assessment of a community health worker program in two Ugandan districts. Int J Equity Health. 2017;16(1):129. https://doi.org/10.1186/s12939-0170619-6.

75. Agarwal S, Lasway C, L'Engle K, Homan R, Layer E, Ollis S, et al. Family planning counseling in your pocket: a Mobile job aid for community health Workers in Tanzania. Glob Health Sci Pract Global Health: Science and Practice. 2016;4(2):300-10. https://doi.org/10.9745/GHSP-D-1 5-00393.

76. Braun R, Lasway C, Agarwal S, L'Engle K, Layer E, Silas L, et al. An evaluation of a family planning mobile job aid for community health workers in Tanzania. Contraception. 2016;94(1):27-33. https://doi.org/10.1016/j.contra ception.2016.03.016.

77. Florez-Arango JF, lyengar MS, Dunn K, Zhang J. Performance factors of mobile rich media job aids for community health workers. J am med inform Assoc. Oxford Academic. 2011:18:131-7.

78. Braun R, Catalani C, Wimbush J, Israelski D. Community Health Workers and Mobile Technology: A Systematic Review of the Literature. PLoS ONE [Internet]. 2013 [cited 2020 May 9];8. Available from: https://www.ncbi.nlm. nih.gov/pmc/articles/PMC3680423/

\section{Publisher's Note}

Springer Nature remains neutral with regard to jurisdictional claims in published maps and institutional affiliations.

Ready to submit your research? Choose BMC and benefit from:

- fast, convenient online submission

- thorough peer review by experienced researchers in your field

- rapid publication on acceptance

- support for research data, including large and complex data types

- gold Open Access which fosters wider collaboration and increased citations

- maximum visibility for your research: over $100 \mathrm{M}$ website views per year

At $\mathrm{BMC}$, research is always in progress.

Learn more biomedcentral.com/submissions 